The INL is a

U.S. Department of Energy

National Laboratory

operated by

Battelle Energy Alliance

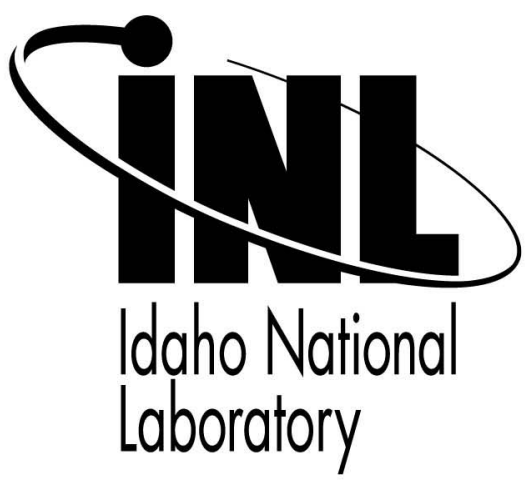

\title{
Conceptual Design of a MEDE Treatment System for Sodium Bonded Fuel
}

\author{
ICONE 16
}

\author{
Carl E. Baily \\ Karen A. Moore \\ Collin J. Knight \\ Peter B. Wells \\ Paul J. Petersen \\ Ali S. Siahpush \\ Matthew T. Weseman
}

May 2008

This is a preprint of a paper intended for publication in a journal or proceedings. Since changes may be made before publication, this preprint should not be cited or reproduced without permission of the author. This document was prepared as an account of work sponsored by an agency of the United States Government. Neither the United States Government nor any agency thereof, or any of their employees, makes any warranty, expressed or implied, or assumes any legal liability or responsibility for any third party's use, or the results of such use, of any information, apparatus, product or process disclosed in this report, or represents that its use by such third party would not infringe privately owned rights. The views expressed in this paper are not necessarily those of the United States Government or the sponsoring agency. 


\section{CONCEPTUAL DESIGN OF A MEDE TREATMENT SYSTEM FOR SODIUM BONDED FUEL}

Carl E. Baily / Idaho National Laboratory

\author{
Karen A. Moore / Idaho National Laboratory
}

\author{
Paul J. Petersen I \\ Idaho National Laboratory
}

\author{
Collin J. Knight I \\ Idaho National Laboratory
}

\author{
Peter B. Wells I \\ Idaho National Laboratory
}

\author{
Matthew T. Weseman / \\ Idaho National Laboratory
}

\begin{abstract}
Unirradiated sodium bonded metal fuel and casting scrap material containing highly enriched uranium (HEU) is stored at the Materials and Fuels Complex (MFC) on the Idaho National Laboratory (INL). This material, which includes intact fuel assemblies and elements from the Fast Flux Test Facility (FFTF) and Experimental Breeder Reactor-II (EBR-II) reactors, as well as scrap material from the casting of these fuels, has no current use under the terminated reactor programs for both facilities. The Department of Energy (DOE), under the Sodium-Bonded Spent Nuclear Fuel Treatment Record of Decision (ROD), has determined that this material could be prepared and transferred to an off-site facility for processing and eventual fabrication of fuel for commercial nuclear reactors. A plan is being developed to prepare, package, and transfer this material to the DOE HEU Disposition Program Office (HDPO), located at the Y-12 National Security Complex in Oak Ridge, Tennessee.
\end{abstract}

Disposition of the sodium bonded material will require separating the elemental sodium from the metallic uranium fuel. A sodium distillation process known as MEDE (MeltDrain-Evaporate), will be used for the separation process. The casting scrap material needs to be sorted to remove any foreign material or fines that are not acceptable to the HDPO program.

Once all elements have been cut and loaded into baskets, they are then loaded into an evaporation chamber as the first step in the MEDE process. The chamber will be sealed and the pressure reduced to approximately 200 mtorr. The chamber will then be heated as high as $650{ }^{\circ} \mathrm{C}$, causing the sodium to melt and then vaporize. The vapor phase sodium will be driven into an outlet line where it is condensed and drained into a receiver vessel. Once the evaporation operation is complete, the system is de-energized and returned to atmospheric pressure.

This paper describes the MEDE process as well as a general overview of the furnace systems, as necessary, to complete the MEDE process.

\section{INTRODUCTION}

This paper reports on initial development of a MEDE treatment process for removing elemental sodium from sodium bonded fuels. This paper is being written during conceptual development and design of a process system to remove sodium from fuel elements for both the FFTF and EBR-II reactors. The materials to be processed are unirradiated fuel elements in addition to some amount of casting scrap. With the shutdown of these two facilities, the remaining unused fuel elements and scrap are no longer useful. It is therefore desired to separate the fuel materials from elemental sodium in preparation for reuse elsewhere. The paper covers both current efforts and some developmental history on the process.

\section{HISTORICAL DEVELOPMENT}

The MEDE process has been developed from a previous process, known as MEDEC (Melt-Drain-Evaporate-Calcine) which was developed and tested by Argonne National 
Laboratory-West (ANL-W) from 1982-1983. The original process development is described in detail in reference 1 . The process was apparently known prior to this development, however, the author has not been able to locate prior references.

As developed in the 1982 process, the MEDEC process involved placing sodium bearing materials in a large vessel and heating them to melt sodium. The bulk of the sodium in the materials could be collected as liquid, and transferred to a separate collection vessel. Once the bulk sodium was removed, the materials were heated to $900^{\circ} \mathrm{F}\left(482^{\circ} \mathrm{C}\right)$ under about $10-20$ mTorr absolute pressure to evaporate the remaining sodium, and this sodium was condensed and captured in a drain tank. The sodium was later pressure transferred to the collection vessel.

Once collected, the sodium was processed to a sodium-oxide waste form in a calciner. This final process was later changed to a "carbonation" process, which resulted in a sodium carbonate waste form. In this manner, the definition of the MEDEC process became known as "Melt-Drain-EvaporateCarbonate." In the MEDEC process, the essential components and features are as follows:

- The Process Vessel, in which the material to be treated is placed. The vessel is designed to allow heating under moderate vacuum to the desired process conditions.

- A condenser, where the sodium vapor driven off from the treated material is condensed back to liquid form.

- A collection vessel, where the condensate is collected.

- A treatment vessel, where the collected sodium is converted to the final waste form, either through calcining or carbonation.
The system was tested both on sodium bonded fuel elements from the Experimental Breeder Reactor-II (EBR-II) and on a large (40-inch diameter) cold trap from the EBR-II reactor. Testing demonstrated that the process could remove sodium from crevices up to 8-inches deep, as well as from a 2-inch long slot, .005-inches wide. Sodium was also removed from mating bolt/nut threads.

Later, in 1985 and 1986, the system was reactivated on a production scale to remove sodium bond from EBR-II fuel elements which had been rejected due to cladding defects. A final total of 1,700 defective fuel elements were processed to remove sodium and allow reclamation of the fuel materials. Figure 2 shows the MEDEC vessel being loaded.

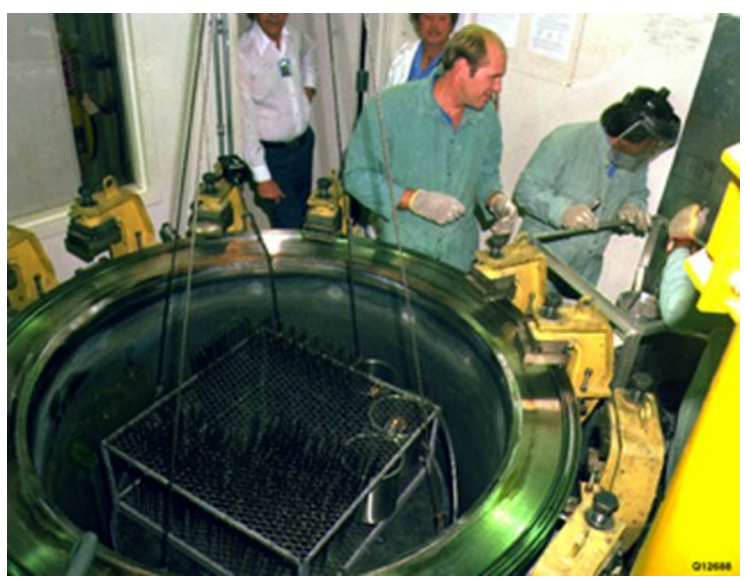

Figure 1 - MEDEC Vessel Being Loaded.

Between 2001 and 2003, testing was performed to qualify a MEDEC process for use on fuels from the FERMI-1 reactor (see reference 2). This testing involved both very small scale glovebox tests and bench scale testing in the HFEF hot cells using irradiated fuels. Figure 3 shows the bench scale MEDEC test system.

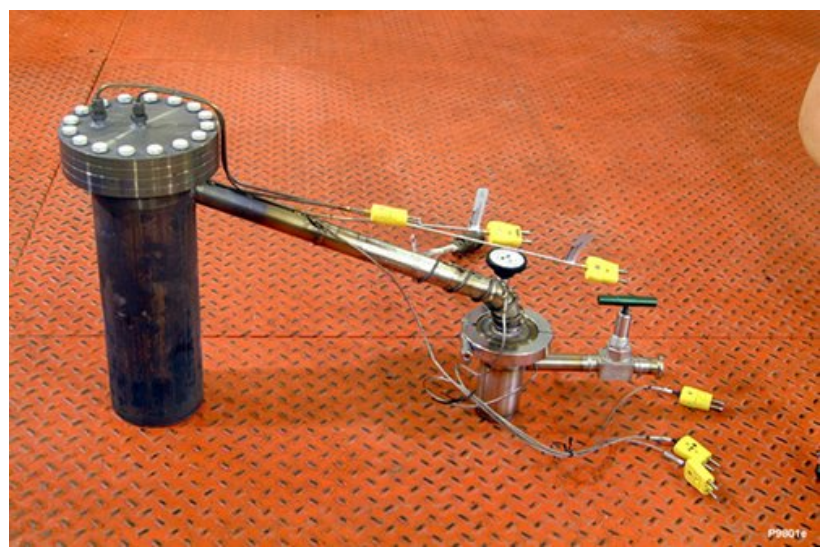

Figure 2 - Bench Scale MEDEC Test System.

In the bench scale tests, the target temperature was raised to $650^{\circ} \mathrm{C}$ to allow use of a less severe 200 mTorr absolute 
pressure. The system demonstrated the ability to remove $>99.95 \%$ of elemental sodium from the sodium bonded elements. The condenser was simply a 1-inch tube (the slanted tube shown in Figure 3) which was exposed to atmosphere. Sodium was collected in the small vessel at right, which was kept at ambient temperature, thus, the collected sodium solidified in the vessel as it was collected. The bench scale tests did not involve testing of the final carbonation step of the treatment process.

\section{DESIGN CONFIGURATION OF MEDE SYSTEM}

The current MEDE process is very similar to the overall bench scale process tested in 2001-2003. The system is designed to remove sodium, which will be separately processed. Therefore, the acronym has been changed to MEDE with the loss of the "carbonation portion" of the process. A further development of the process is the deletion of the initial melt-drain steps. One outcome of the bench scale testing was the observation that there was little draining of sodium from fuel elements due to the small size of the element claddings and small annuli. Thus, for these items, all sodium removal will occur by evaporation and condensation. Figure 4 shows an artist's rendition of the layout of the basic components of the MEDE system.

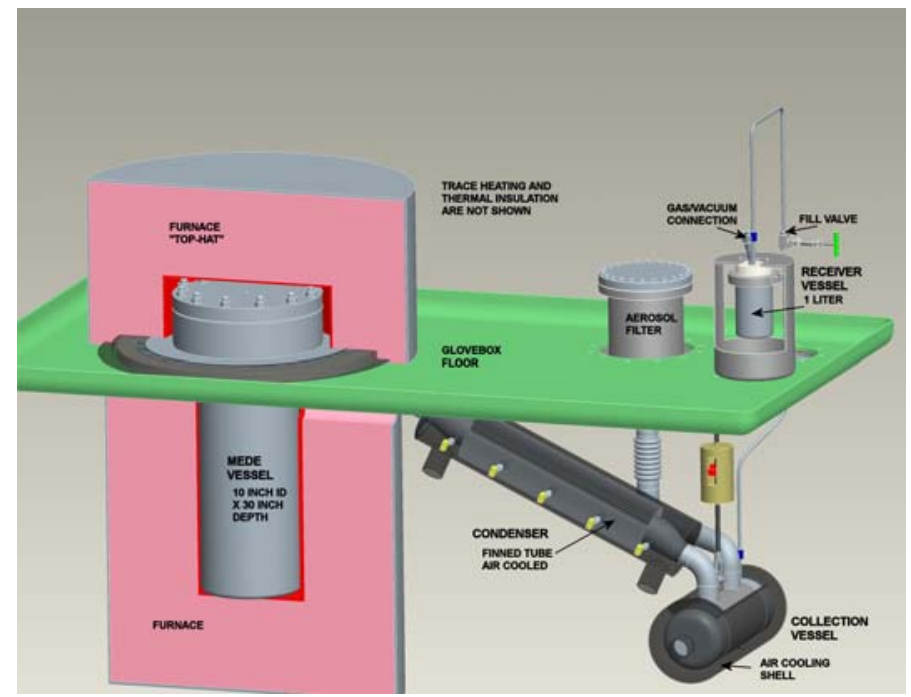

Figure 3 - Conceptual MEDE System.

The MEDE system being developed will be installed in a glovebox. To accommodate the desired fuel loading, a vessel of 10-inches ID and approximately 30-inches internal length will be used. The vessel will be installed to the glovebox floor and insulated from the floor to the extent practical. A furnace will be installed around the vessel. A portion of the furnace is located outside the glovebox, and a removable "top-hat" portion is located inside the glovebox. An inclined air-cooled condenser is used to condense the sodium vapor, while another air cooled collection vessel is installed to collect the condensed sodium. The condenser, collection vessel, and connecting piping are fitted with external trace heating and thermal insulation (not shown) to maintain temperatures above the solidification temperature of sodium $\left(98^{\circ} \mathrm{C}\right)$.

An air cooled condenser was chosen for the system since air is not subject to phase change or chemical breakdown due to high temperatures. Since the condenser must operate at bulk temperatures of $100^{\circ} \mathrm{C}$ or higher, water would need to be pressurized to be used as a heat transfer fluid. Other high temperature heat transfer fluids such as silicone and hydrocarbon based heat transfer oils were researched, but were found not suitable. Heat transfer coefficients for sodium condensation are extremely high (approximately 30,000 Watt $/ \mathrm{m}^{2 \circ} \mathrm{C}$ ) as opposed to fluid heat transfer coefficients of around $600-1000 \mathrm{Watt} / \mathrm{m}^{2 \circ} \mathrm{C}$ for forced convection with heat transfer fluids. Due to this large difference, localized fluid temperatures could reach the sodium evaporation temperatures at the condenser wall near the sodium inlet, even though bulk temperatures were much lower. These temperatures would be high enough to drive the chemical breakdown of the fluids.

Sodium is collected in a small collection vessel, which also provides connection for the vacuum system. It is presently anticipated that the collection vessel will normally be maintained just hot enough to keep the sodium from freezing. Since sodium will initially enter the collection vessel at near the condensing temperature (significant sub-cooling in the condenser is not presently expected), the collection vessel is fitted with an air cooling shell. Vacuum for the MEDE vessel is provided by drawing through the collection vessel and condenser. By cooling the sodium in the collection vessel as much as practical, the amount of sodium vapor in the collection vessel is minimized. This will help prevent introduction of sodium vapor or aerosol downstream of the collector.

Once the sodium has been collected, it is transferred to the receiver vessel. This transfer is performed by pressurizing the collection vessel with inert gas, evacuating the receiver vessel, and using the pressure differential to drive sodium to the receiver vessel. The receiver vessel is designed as a removable single-use vessel, which will be replaced after it is filled. The receiver vessels contain the sodium for transport to a disposition facility. The receiver vessel will not be heated because it is desired that the sodium freeze in this vessel.

An aerosol filter using sintered stainless steel filter elements is provided downstream of the condenser. The name is really a bit misleading since under vacuum there should be little or no aerosol transport. During evaporation/condensation of sodium, this aerosol filter will provide a large, relatively cool surface area to condense and hold any sodium vapor which might get past the collection vessel. During sodium transfer operations and the venting of the collection vessel, the trap would collect any aerosol that might be carried by the vented gas. As long as temperatures are relatively low, the amount of aerosol collected should be very small.

Prepared for the U.S. Department of Energy Office of Nuclear Nonproliferation and Security Affairs Under DOE Idaho Operations Office Contract DE-AC07-05ID14517 


\section{INTENDED OPERATIONAL SEQUENCE}

The following sequence of operations is prototypical. It is intended to perform an extended checkout and test program to establish the final operational control scheme for the system:

1. Control systems are energized.

2. Trace heating systems are energized.

3. The MEDE vessel furnace is energized.

4. The vacuum system is started and an initial vacuum of 200 milliTorr or less is established.

5. All system temperatures and pressures are expected to reach steady state before sodium evaporation starts (MEDE vessel heater startup may be delayed if this is not demonstrated during qualification testing.).

6. The vacuum pump will be secured when an initial pressure of 20 milliTorr is reached. The vacuum pump will then be operated only periodically as required to maintain pressures near saturation for the MEDE vessel.

7. Once the temperature of the treatment payload reaches saturation temperature for sodium, the evaporation of sodium begins.

8. As the condenser temperature starts to increase due to condensation, the air cooling system starts to provide air to the condenser shell.

9. If condenser temperatures rise high enough, indicating the condenser is reaching its limiting condensation rates, furnace power is reduced.

10. Condensed sodium will enter the collection vessel. Its air cooling system lowers the sodium temperature from evaporation temperature to a temperature just sufficient to prevent freezing.

11. The vacuum pump will be periodically operated to remove non-condensable gasses from either small system leaks or bake-out of gas from the treatment payload.

12. The system is maintained at temperature for sufficient time to ensure that the entire payload has reached temperature and sodium has had sufficient time to be removed from crevices and small annuli.

13. When treatment is completed, the MEDE vessel heaters are shut down. The collection vessel remains heated to keep the sodium molten.

14. Once the system has cooled sufficiently to ensure that no sodium vapor remains, the sodium receiver vessel is evacuated and the pressure in the main portion of the system is raised to approximately 2 psig.

15. The manual sodium valve is opened to allow transfer of sodium to the receiver vessel. The pressure differential between the receiver vessel and collection vessel will drive sodium flow.

16. The receiver vessel is allowed to cool until the surface temperature is approximately $60 \mathrm{C}$.
17. The receiver vessel is then removed and a new vessel installed. The removed vessel is capped and prepped for removal from the glovebox.

18. Once the MEDE vessel temperatures have dropped sufficiently, the vessel lid may be opened. Additional cooling time may be required before the basket and payload are cool enough to be handled.

By operating the vacuum pump only as necessary, the rate of sodium removal will be inherently limited by the heat removal capacity of the condenser. If the vacuum pump were to be operated continuously, it is probable that the rate of sodium evaporation would exceed the condenser capacity at least for short periods. In this situation, sodium vapor would be drawn downstream and condensation of sodium could occur in the collection vessel, aerosol filter, or even the vacuum system.

There is considerable question as to how the sodium removal will proceed. If a significant portion of the sodium melts and relocates to the bottom of the MEDE vessel, the evaporation will proceed rapidly for that portion of the sodium, driven by the power capacity of the lower furnace heaters. If this does not occur and the sodium remains in the treatment package, the sodium evaporation will proceed much more slowly, driven by radiation transfer of heat into the package and the conduction of heat through the package. The inherent process limits to the condensation rate are the heat transfer limit for the condenser and the maximum heat which can be transferred into the payload by the furnace.

\section{FURTHER DEVELOPMENT TESTING}

The MEDE system will eventually be installed in an inert atmosphere radiological glovebox in a nuclear facility at Idaho National Laboratory. Access to this facility for testing and process development is very difficult. The system will therefore be initially installed in another open laboratory facility. It will be installed in a simplified testing glovebox which will allow easy access for testing and research personnel.

While the general MEDE process is relatively well understood, there is considerable opportunity to adjust and optimize the process for this new system. There are a number of questions for which the previous tests do not provide direct answers. There are also several areas where it appears that improvements may be made on previous systems. Specific questions which will be investigated further include:

- Previous MEDE/MEDEC systems have operated the vacuum system continuously during evaporation of sodium. If the evaporation rate exceeds the capabilities of the condenser, sodium vapor can be drawn into the vacuum system. It is proposed that the

Prepared for the U.S. Department of Energy Office of Nuclear Nonproliferation and Security Affairs Under DOE Idaho Operations Office Contract DE-AC07-05ID14517 
vacuum system be secured for most of the process, and the condenser used to maintain vacuum. In this manner, if the evaporation temporarily exceeds the condenser capability, the system pressure will rise and suppress evaporation. In essence, the system will be self-regulating. If there is significant leakage of noncondensable gas into the system, or if there is gas released from the payload, this system may not function. Testing will show if the generation / inleakage of non-condensable gas requires that the vacuum pump be continuously operated.

- In the MEDEC process of 2001-2003, the collection vessel was operated in a cold state and sodium was allowed to freeze in the collection vessel. This could reduce problems with downstream condensation of sodium, but might result in plugging up the collection vessel inlet if that location becomes cold enough. It is intended to see if collection at temperatures below $100^{\circ} \mathrm{C}$ is practical or desirable.

- The 2001-2003 tests showed no detectable sodium transport to the vacuum system. This will also be investigated in development testing of the new system. If it is shown that sodium does not transport downstream of the condenser, it might be possible to reduce the vacuum system complexity. If sodium transport is apparent, testing will allow establishment of appropriate intervals for filter examination and change out.

- Since there is no direct way to measure the temperatures at the center of a treatment payload, it will be necessary to determine treatment parameters to ensure that an entire payload reaches the desired treatment temperature. It is planned to treat surrogate materials simulating the payloads to be treated. These surrogate materials will duplicate critical dimensions of the materials to be treated, and will be loaded with prototypical amounts of sodium. It is planned to provide additional test instrumentation in the MEDE vessel (through provision of a test closure lid) to allow required treatment parameters to be established.

- Surrogate test items will be prepared which closely simulate the important features of the items to be treated. These surrogate items will be loaded with sodium, and an assay process will be.

\section{FUTURE REPORTING OF RESULTS}

The authors intend to provide the results of the development testing in a separate report. It is also intended that the final treatment program will be the subject of its own report.

\section{ACKNOWLEDGEMENTS}

This manuscript has been authored by Battelle Energy Alliance, LLC under Contract No. DE-AC07-05ID14517 with the U.S. Department of Energy. The United States Government retains and the publisher, by accepting the article for publication, acknowledges that the United States Government retains a nonexclusive, paid-up, irrevocable, world-wide license to publish or reproduce the published form of this manuscript, or allow others to do so, for United States Government purposes.

\section{REFERENCES}

1. ANL-86-50, Sodium Waste Technology, A Summary Report, C.S. Abrams and L.C. Witbeck, pub. Argonne National Laboratory, 1996.

2. ANL Document F3640-1300-ES, MEDEC Treatment of Fermi-1 Sodium-Bonded Blanket Fuel in Preparation for Final Geologic Disposal, Humberto Garcia, Steven Herrmann, Robert Pahl, David Sell, Karen Toews-Howden, Richard Rigg, pub. Argonne National Laboratory, 2003. 